\title{
Multiple-file vs. single-file endodontics in dental practice: a study in routine care
}

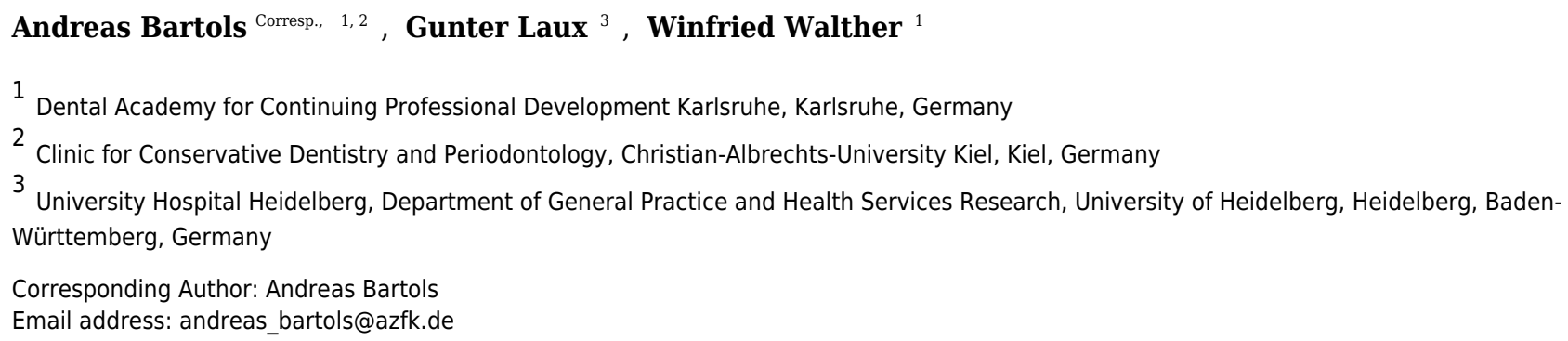

Background. Little is known about the differences of rotary multiple file endodontic therapy and single-file reciprocating endodontic treatment under routine care conditions in dental practice. This multicenter study was performed to compare the outcome of multiple-file (MF) and single-file (SF) systems for primary root canal treatment under conditions of general dental practice regarding reduction of pain with a visual analogue scale (VAS 100), improvement of oral-health-related quality of life (OHRQoL) with the german short version of the oral health impact profile (OHIP-G-14) and the speed of root canal preparation. Materials and Methods. Ten general dental practitioners (GDPs) participated in the study as practitioner-investigators (PI). In the first five-month period of the study the GDPs treated patients with MF systems. After that the GDPs treated the patients in the second five-month period with a SF system (WaveOne). The GDPs documented the clinical findings at the beginning and on completion of treatment. The patients documented their pain and OHRQoL before the beginning and before completion of treatment. Results. 599 patients were included in the evaluation. 280 patients were in the MF group, 319 were in the SF WaveOne group. In terms of pain reduction and improvement in OHIP-G-14 the improvement in both study groups (MF and SF) was very similar based on univariate analysis methods. Pain reduction was 34.4 (SD 33.7) VAS (MF) vs. 35.0 (SD 35.4) VAS (SF) ( $p=0.840)$ and the improvement in OHIP-G-14 score was 9.4 (SD 10.3) (MF) vs. 8.5 (SD 10.2) (SF) ( $p=0.365)$. The treatment time per root canal was $238.9 \mathrm{sec}$ (SD $206.2 \mathrm{sec}$ ) (MF) vs. $146.8 \mathrm{sec}$ (SD $452.8 \mathrm{sec})(\mathrm{SF})(p=0.003)$. Discussion. Regarding improvement of endodontic pain and OHRQoL measure with OHIP-G-14 there were no statistical significant differences between the SF und the MF systems. WaveOne prepared root canals significantly faster than MF systems. 
1 Multiple-file vs. single-file endodontics in dental practice: a study in routine 2 care.

3 Dr. Andreas Bartols, MA ${ }^{1,2}$, Prof. Dr. Gunter Laux ${ }^{3}$, Prof. Dr. Winfried Walther ${ }^{1}$

51 Dental Academy for Continuing Professional Development, Karlsruhe, Germany

62 School for Dental Medicine, Christian-Albrechts-University Kiel, Clinic for Conservative

7 Dentistry and Periodontology, Kiel

83 University Hospital Heidelberg, Dept. of General Practice and Health Services Research,

9 Heidelberg, Germany

12 Corresponding Author: Dr. A. Bartols, Dental Academy for Continuing Professional Development, Lorenzstraße 7, 76135 Karlsruhe, Germany andreas_bartols@azfk.de

Phone 00497219181101

17 Running head: Multiple-file vs. single-file endodontics 
Background. Little is known about the differences of rotary multiple file endodontic therapy and single-file reciprocating endodontic treatment under routine care conditions in dental practice. This multicenter study was performed to compare the outcome of multiple-file (MF) and singlefile (SF) systems for primary root canal treatment under conditions of general dental practice regarding reduction of pain with a visual analogue scale (VAS 100), improvement of oral-healthrelated quality of life (OHRQoL) with the german short version of the oral health impact profile (OHIP-G-14) and the speed of root canal preparation.

Materials and Methods. Ten general dental practitioners (GDPs) participated in the study as practitioner-investigators (PI). In the first five-month period of the study the GDPs treated patients with MF systems. After that the GDPs treated the patients in the second five-month period with a SF system (WaveOne). The GDPs documented the clinical findings at the beginning and on completion of treatment. The patients documented their pain and OHRQoL before the beginning and before completion of treatment.

Results. 599 patients were included in the evaluation. 280 patients were in the MF group, 319 were in the SF WaveOne group. In terms of pain reduction and improvement in OHIP-G-14 the improvement in both study groups (MF and SF) was very similar based on univariate analysis methods. Pain reduction was 34.4 (SD 33.7) VAS (MF) vs. 35.0 (SD 35.4) VAS (SF) (p=0.840) and the improvement in OHIP-G-14 score was 9.4 (SD 10.3) (MF) vs. 8.5 (SD 10.2) (SF)

$37(\mathrm{p}=0.365)$. The treatment time per root canal was $238.9 \mathrm{sec}(\mathrm{SD} 206.2 \mathrm{sec})(\mathrm{MF}) \mathrm{vs} .146 .8 \mathrm{sec}$. 38 $(\mathrm{SD} 452.8 \mathrm{sec})(\mathrm{SF})(\mathrm{p}=0.003)$ 
39 Discussion. Regarding improvement of endodontic pain and OHRQoL measure with OHIP-G-14

40 there were no statistical significant differences between the SF und the MF systems. WaveOne

41 prepared root canals significantly faster than MF systems.

42 
43

44

45

46

47

\section{Introduction}

Clinical endodontic research is mainly conducted by specialists or specialized university centers (Friedman et al. 2010; $\mathrm{Ng}$ et al. 2007). The predominant types of such studies are retrospective observational studies, prospective cohort studies and a few randomized controlled trials (RCTs) (Ng et al. 2007). On account of the controlled study design, these studies have greater internal evidence and are classified as efficacy studies (Pfaff et al. 2011). The effectiveness of endodontic interventions under everyday general dental care conditions has so far been hardly investigated (Nixdorf et al. 2012). Yet, patients treated in specialized centers can differ systematically from patients treated in routine care (Hulley 2013).

A commonality of many experimental endodontic studies is the low number of cases (Peters \& Wesselink 2002; Pettiette et al. 2001; Weiger et al. 2000). Larger case numbers are described for retrospective observational studies and prospective cohort studies, which, however, are often conducted without controls ( $\mathrm{Ng}$ et al. 2007). Convincing results though can be obtained in studies if they include an adequate number of cases (Hulley 2013). Since only few experimental endodontic studies have been made and many of them are lacking sufficient patient numbers, one could assume this to be an indication of considerable feasibility problems of such studies.

Reciprocating single-file (SF) systems are the latest stage of development of nickel-titanium (NiTi) instruments for the preparation of root canals (Bürklein et al. 2013; Yared 2008). During the last years several systems as Reciproc (VDW, Munich, Germany), WaveOne (Dentsply, Konstanz, Germany), Genius files (Ultradent, South Jordan, UT, USA) or the Twisted Files Adaptive System (Kerr, Orange, CA, USA) with a combination of rotary and reciprocating movement were introduced into the market. Our knowledge of the clinical effects of using 
65

66

67

different systems for root canal preparation is limited (Schäfer et al. 2004). The Swedish Council on Health Technology Assessment stated in its Systematic Review of Methods of Diagnosis and Treatment in Endodontics that the use of new tools facilitates the technical procedures of root canal treatment and that therefore investigations are needed, which influence these techniques have on everyday general practice (Bergenholtz et al. 2012).

Typically, new instrument systems are investigated in in-vitro-studies with extracted teeth (Bürklein et al. 2013) or root canal models (Goldberg et al. 2012). In such studies, the outcomes are mainly surrogate parameters, such as root canal straightening, preparation faults, preparation time in a workbench situation etc. the clinical significance of which can only be estimated to a limited extent (Hülsmann 2013). Most of the few clinical trials available investigated only one instrument system (Fleming et al. 2010; Su et al. 2011) and rarely allow a comparison with other instrument systems (Schäfer et al. 2004). Recently some randomized controlled trials were published, that investigated single and multiple file systems for endodontic treatment regarding pain reduction after treatment and improvement in quality of life (Kherlakian et al. 2016; Pasqualini et al. 2015; Relvas et al. 2015). It is unclear if there exists an effectiveness-gap (Pfaff et al. 2011) between the results of these controlled studies under the optimal treatment conditions of specialized treatment providers and the use of rotary multiple-file (MF) and SF systems in general dental practice.

Therefore research is needed when new endodontic techniques are introduced into dental practice. The study we performed, investigates the effects of these endodontic techniques on dental practice. For this purpose it uses the methods of health services research which studies care processes under everyday conditions of dental practice (Pfaff et al. 2009). Short-term Patient-relevant outcomes were in the center of the study. 
88 The design we chose was a multicenter study in routine care. We started by evaluating the

89 outcome of endodontic treatment using conventional MF instrument systems for root canal

90 preparation. Then the practitioner-investigators (PIs) were trained in single-file (SF) endodontics

91 (WaveOne-Instruments, Dentsply Maillefer, Ballaigues, Switzerland). Subsequently we

92 evaluated the outcome of endodontic treatments using WaveOne.

93 The following research hypotheses were investigated in our study:

94

95

96

97

98

99

100

101

102

103

104

105

106

107

\section{Primary outcome criterion}

Does root canal preparation using SF root canal instruments lead to more or less reduction of patients' endodontic pain compared to using rotary MF instrument systems?

\section{Secondary outcome criterion}

Does root canal preparation using SF root canal instruments lead to more or less reduction of patients' oral-health-related quality of life compared to using rotary MF instrument systems?

\section{Tertiary outcome criterion}

Does root canal preparation using a single-file system require less time compared to the MF systems?

\section{Methods}

\section{Study Design}

We performed the present study as a multicenter clinical study. For the purpose of this study we formed a network of ten general dental practitioners (GDPs). They acted as PIs. We conducted the study in two phases (Figure 1). In the first 5-month phase the GDPs performed the 
108 endodontic therapy with different rotary nickel-titanium (NiTi) MF systems (Table 1).

109 Subsequently the GDPs were trained for the use of the WaveOne SF system (Maillefer,

110 Ballaigues, Switzerland). In the second 5-month phase the PIs treated the patients with SF

111 WaveOne instruments exclusively. After each 5-month phase there was a 3-month follow-up so

112 that treatments started could be completed.

113 The authors of this study acted solely as investigator and did not treat patients.

114 The study was conducted in conformity with the Declaration of Helsinki and the Professional

115 Code for Physicians of the Medical Council of the State of Baden-Württemberg. The Ethics

116 Committee of the Baden-Württemberg Medical Council reviewed the study and approved it (AZ:

117 F-2011-034-z).

\section{Participants}

119 Patient eligibility and recruitment

120 All patients of the ten PIs who required endodontic therapy were consecutively assessed for 121 eligibility.

122 The following inclusion criteria were defined: patients had to be at least 18 years old and in need 123 of initial orthograde root canal treatment.

124 The following exclusion criteria were defined: Patients with hopeless teeth for periodontal or

125 restorative reasons, patients treated for emergency reasons only, more than one symptomatic

126 tooth requiring endodontic treatment at the same time in one patient, patients with other oral

127 findings causing pain, patients with craniomandibular dysfunction and communication 
128 difficulties (eg, patients were not able to read, understand and complete the study questionnaires

129 in German language).

130 All patients were recorded by the assistant staff of the dental practice and asked for the reason if

131 they refused to participate. Every patient was given the study education and information

132 documents (informed consent) that had to be signed and submitted by the patient before the 133 patient was included in the study.

134

135

136

137

138

139

140

141

142

143

144

145 146

147

148

149

\section{Practitioner Investigators (PIS)}

The ten dentists who participated in the study were general dental practitioners with at least two years of professional experience in a general dental practice and without endodontic specialization. All participating dentists worked under the conditions of the German "Statutory Health Insurance". The PIs were chosen as a convenient sample of dentists that wanted to change their endodontic treatment to single file systems within the next 6-12 months anyway. All practices were located in southwest Germany.

All PIs were familiar with root canal preparation using rotary NiTi instruments (Tab. 1) and used them routinely in their practice. All dentists followed the "Good Clinical Practice: Root Canal Treatment" Guideline of DGZMK (German Society of Dental, Oral and Craniomandibular Sciences) (Hülsmann \& Schäfer 2005) which contains essential key points of the Quality guidelines for endodontic treatment of the European Society of Endodontology (Endodontology 2006).

47 Study initiation at the PIs

Before the study started, all participating PIs were visited by the principal investigator $(A B)$ in their practice. The dentists were informed about the object and purpose of the study and its 
150 practical implementation. Each PI was given a copy of the study protocol and all other study

151 relevant files. The dentists were informed about the planned procedure with regard to patient

152 recruitment, education/information and treatment.

\section{Interventions}

154 In the first phase of the study from 09/2011 to 02/2012 all endodontic treatments were performed

155 with rotary NiTi MF systems (Figure 1). All MF systems were used according to the

156 manufacturer's instructions. In 03/2012 the PIs were trained for the SF system. The training

157 course explained the theoretical bases of the WaveOne System (Maillefer, Ballaigues,

158 Switzerland) and provided hands-on training on extracted teeth. After this one-day training

159 course every participating dentist was able to prepare root canals by the new method in a reliable

160 way. The training was followed by a two-week implementation phase in all participating dental

161 offices. During that time the PIs should learn to treat patients with the new instruments and gain

162 experience. In case of difficulties this procedure offered the chance of clarifying problems. In the

163 second phase of the trial from 04/2012 to 08/2012 all endodontic treatments were performed with

164 the SF system. All other variables of the practice setting and the treatment procedures remained

165 unchanged.

166 Before treatment, the affected tooth was anesthetized by local anesthesia. After local anesthesia

167 the endodontic access cavity was prepared. All teeth were isolated with a rubberdam. Root canals

168 were probed with K-steel files of ISO sizes $06,08,10$ and 15, in order to create a glidepath up to

169 ISO 15 throughout all phases of the study. The working length was determined electrometrically

170 and/or by X-ray. The dentists prepared the root canals according to the details provided by the

171 manufacturers of the different rotary preparation systems. In the second study phase the root 
172 canals were prepared with the WaveOne instruments according to the manufacturer's

173 instructions. If the dentists needed an apical preparation size that is not included in the WaveOne

174 System, the last ISO size was followed up by a single hand instrument of the desired size. During

175 rotary or reciprocating preparation the root canals were rinsed with $1-3 \% \mathrm{NaOCl}$ between every

176 rotary instrument or in case of the SF system between every 3-4 picks with the WaveOne file.

177 After complete preparation of the root canals they were irrigated with a final irrigation of $\mathrm{NaOCl}$

$178 \quad 1-3 \%$ and a calcium hydroxide dressing or the root canal filling was placed. After that the tooth

179 was sealed provisionally bacteria-proof with a temporary bacteria tight seal. In the last

180 appointment the root canal filling was placed or in case of single-visit endodontics a definitive

181 coronal filling was applied.

\section{Outcomes}

183 The primary outcome of reduction of endodontic pain and the secondary outcome of

184 improvement of oral-health-related quality of life was measured with a patient questionnaire.

185 The questionnaire assessed the pain by the Visual Analog Scale (VAS 100) (Turk 2011) and the

186 oral-health-related quality of life with the items of the short version of the oral health impact

187 profile (OHIP-G-14) (John et al. 2004) wich is the German translation of OHIP-14 (Slade 1997).

188 The patients were asked about the biggest complaints (consisting of the VAS 100 and OHIP-

189 G14) without pain medication in the week before treatment and in the week before completion of

190 treatment. This was two weeks after initial treatment and in connection with either the placement

191 of the root canal filling or the definitive coronal filling of the tooth. The questionnaires were

192 filled in by the patients before treatment started or while local anesthesia was taking effect. Any

193 patient questions were answered by the dental team. 
194 The time needed for root canal preparation was measured by the dental assistant staff. The 195 measurement started when the first rotating or reciprocating instrument was placed in the root

196

197

198

199

200

201

202

203

204

205

206

207

208

209

210

211

212

213

214

215

canal and ended when the last instrument was removed. The root canal recapitulations during preparation and the irrigations were included in the time measurement. Probing and glidepath preparation before using the rotary instruments were not included in the time measurement. Nor were the final irrigation of the root canals and the placement of a dressing included. When a tooth had several root canals, the total preparation time of all canals was measured and divided by the number of root canals in order to determine the preparation time per canal.

\section{Further questionnaires and data collection}

In the PI questionnaires the clinical findings (dental chart, sensitivity test, percussion test, apical pressure point, periodontal probing depth, radiographic presence of apical periodontitis, number of prepared root canals, presence of fistulae), the time needed for root canal preparation, instrument fractures and procedural events were documented. In addition, a consecutive patient $\log$ was introduced to record, if possible, the patient's reason for rejecting participation. The patient forms included the patient's informed consent to participate in the trial, a questionnaire asking for demographic and basic medical data, and the above described pain questionnaire which consisted of the VAS and the Items of OHIP-G-14.

All patients that qualified for participation in the study were informed about the study by the PI personally. All PI forms were filled in by the assistant dental staff. The patient questionnaires were filled in by the patients themselves. All patient questionnaires were pseudonymized and collected in a sealed box. The PI forms were pseudonymized in the same way to be able to match the patient data and the PI data in the subsequent evaluation. 
216 The pain questionnaires were completed by the patients immediately before treatment started.

217 The demographic data could be provided at any time, but were requested on completion of the

218 treatment at the latest. The pain questionnaires were completed by the patients again 14 days

219 after treatment. The PIs' treatment was taken down on record. The time required for root canal

220 preparation was measured by the dental assistant staff.

221 The questionnaires were handed over to the principal investigator $(\mathrm{AB})$ at the end of the first and

222 at the end of the second trial phase for evaluation.

\section{Safety measures}

224 Before treatment started, each patient participating in the study was informed about the

225 endodontic risks in the same way as it is usually done before endodontic therapy. The patient

226 was informed in particular about events, such as instrument fractures and other complications

227 that may occur in root canal preparation and could lead to the extraction of the tooth affected.

228 The patient was also informed, that root canal treatment is the last attempt to save a tooth. The

229 information was provided by the PI and an additional education and information questionnaire. If

230 in the course of the trial the complication of an instrument fracture occurred, the patient would

231 be informed about it. This information was provided by an information questionnaire for

232 instrument fractures.

\section{Sample Size Calculation and Statistics}

234 For sample size calculation we had to consider the sample design which was characterized by a

235 2-stage structure (dental practice, patient). This cluster sample made special demands on both

236 sample planning and the analysis of the results (Donner \& Klar 2000). 
237 To calculate the case number, the following parameters were defined: Significance level: 0.05 ,

238 Power: $80 \%$ and Number of clusters (dental practices): 10

239 Moreover, based on the analysis of similar studies (Pak 2012), the most realistic assumptions

240 possible were made about the clinically relevant difference of the VAS 100 (Visual Analog

241 Scale) and the ICC (Intra Cluster Correlation Coefficient) which is a measure for the

242 homogeneity in relation to a target variable of interest within the cluster: $\triangle \mathrm{VAS}=20(20 \%)$ and

$243 \quad \mathrm{ICC}=0.04$.

244 For case number calculation a validated software tool was used which determined the number of

245 trial units (patients) per cluster (practice) on the basis of the parameters specified above

246 (Campbell et al. 2004).

247 The resulting number of patients was 28 per dental practice and every trial phase. This number 248 appeared realistic in terms of feasibility. In view of the basic statistical data on dental care in

249 Germany (KZBV 2011), a conservative estimate showed that one GDP performs about 60 root

250 canal treatments per year. This means that 10 participating GDPs should be able to recruit the

251 required case number in each of the trial phases.

252 The results were calculated with the SPSS (Version 21, Win x64) statistical system and SAS

253 (Version 9.2, Win x64). With the PROC MIXED procedure (Singer 1998) SAS offers options for 254 explicitly considering potential cluster effects (here: several data collection units per dental 255 office) in the overall regression model.

256 Assessment of potential covariates 
257 Besides collecting the data for the primary outcome we assessed other dentist- and patient-

258 related as well as treatment-specific covariates. This was done with a questionnaire for

259 demographic information which also documented the patients' basic medical data. In addition,

260 the PIs recorded the dental chart and treatment-specific findings (tooth sensitivity before

261 treatment, apical translucency, percussion test, apical pressure point and fistula).

\section{Study termination criteria}

263 It was planned to terminate the study when two weeks after root canal preparation by the new

264 single-file method the patient's pain was $40 \%$ above the expected level. The study would also

265 have been terminated if single-file endodontics would have caused markedly more instrument

266 fractures than expected. If during the study more than three instrument fractures had already

267 occurred in the first 20 single-file treatment cases, the study would have been terminated.

\section{Results}

269 The ten PIs screened a total of 668 patients who met the study inclusion criteria. Of the 668

270 patients screened, $62(9.2 \%)$ could not be included in the study primarily. In the course of the

271 study, $7(1.0 \%)$ patients did not keep the agreed appointments for starting the treatment (Figure

272 2). The remaining 599 patients were included into the study for statistical analyses. Thus, the

273 number of patients actually included was $10.3 \%$ higher than the minimum required case number

274 of 560 determined by power analysis.

275 Table 1 shows the number of patients that were recruited by the PIs. During both trial periods the

276 individual participating GDPs recruited between 19 (PI 8) and 144 (PI 7) patients. All GDPs

277 together included $280(46.7 \%)$ patients for MF treatment and 319 (53.3\%) patients for SF

278 treatment. The distribution between the groups was nearly equal. The average age of the patients 
279 was 50.2 (SD 15.7) years. The distribution of the patients to the various participating GDPs

280 differed $\left(\chi^{2} ; \mathrm{P}<0.001\right)$ whereas the age distribution across the study groups (MF and SF) showed

281 no statistical differences ( $T-T e s t ; ~ P=0.991$ ) and was similar in both groups, i.e. 50.1 (SD 15.0)

282 years in MF and 50.2 (SD 16.4) in SF. More men (53.1\%) were treated than women. The gender

283 distribution showed no statistical differences in the individual dental practices $\left(\chi^{2} ; \mathrm{P}=0.082\right)$ nor

284 in the study groups $\left(\chi^{2} ; \mathrm{P}=0.458\right)$. The various types of vocational qualification, as stated by the

285 study participants, differed in the individual practices $\left(\chi^{2} ; \mathrm{P}<0.001\right)$ but not in the study groups

$286\left(\chi^{2} ; \mathrm{P}=0.102\right)($ Table 2).

287 The return rates of the various questionnaires that had to be completed by the patients and the

288 participating GDPs were between $86 \%$ for the follow-up patient pain questionnaire and up to

$28997 \%$ for the questionnaire to be completed by the GDPs. The return rate of the patient pain

290 questionnaire before treatment was $94 \%$ and for the demographic data questionnaire it was $90 \%$

291 (Table 3).

292 In the course of the study slightly more maxillary (53.7\%) teeth were treated (Table 4$)$. The

293 distribution of the different types of teeth showed no significant differences between the two

294 study groups $\left(\chi^{2} ; \mathrm{P}=0.255\right)$.

Evaluation of the primary outcome criterion

296 For the evaluation of the primary outcome, i.e. post-operative reduction of patients' endodontic

297 pain and improvement of oral-health-related quality of life, we measured pain reduction via VAS

298100 and the OHIP-G14 score. Both values were measured before root canal treatment and 14

299 days after treatment. Then we compared the different study groups (MF and SF). 
300 The mean pain score before root canal treatment for MF was 42.3 (SD 32.6) VAS and for SF 43.9 (SD 32.0) VAS and decreased to 10.0 (SD 18.6) VAS (MF) and 9.3 (SD 19.2) VAS (SF).

302 The mean OHIP-G 14 score before root canal treatment for MF was 12.5 (SD 10.6) and for SF

30313.0 (SD 10.8) and decreased to 3.6 (SD 5.1) (MF) and 4.6 (SD 6.5) (SF).

304 For pain reduction and OHRQoL univariate analysis showed a very similar improvement in both 305 study groups (MF and SF)

306 (a) Pain reduction 34.4 (SD 33.7) VAS (MF) vs. 35.0 (SD 35.4) VAS (SF) (p=0.8)

307 (b) Improvement of oral-health-related quality of life according to OHIP-14 score: 9.4 (SD 10.3) (MF) vs. $8.5(\mathrm{SD} 10.2)(\mathrm{SF})(\mathrm{p}=0.4)$

309 The differences between the study groups were not significant.

310 Multivariate analysis of variance (MANOVA) taking the additional factor "single vs. multiple-

311 visit treatment" into account did not reveal any significant influence of the factors "study group 312 (MF or SF)", "single vs. multiple-visit" or an interaction of the two regarding pain reduction. For 313 improvement of OHIP-14 score there was an overall significant influence $(\mathrm{p}=0.03)$ with "single314 visit" treatments having a significantly $(\mathrm{p}=0.01)$ lower improvement than "multiple-visit". But 315 further analyses showed that OHIP-14 scores for "single-visit" treatments (10.7 (SD 9.9)) were 316 already significantly $(\mathrm{p}=0.06)$ lower before treatment than for "multiple-visit" treatments $(13.6$ 317 (SD 10.9)) and dropped to almost the same levels before completion of treatment (4.1 (SD 5.9) 318 vs. $4.2(\mathrm{SD} 6.0)$.

\section{Evaluation of the secondary outcome criterion}


320 For the speed of root canal preparation, univariate analysis showed a significant difference

321 between the study groups MF and SF:

322 (c) Duration of treatment per root canal (in sec): 239 (MF) vs. 147 (SF) (P=0.003)

323 For (c) a multivariate analysis was made taking into consideration the dentist- and patient-related 324 as well as treatment-specific covariates:

325 - Gender of dentist

326 - Gender of patient

327 - Age of patient

328 - Comorbidities of the patient (none, hypertension, DM(I or II), asthma)

329 - DMFT Index

330 - Tooth

331 - Tooth sensitivity before treatment (positive/negative)

332 - Apical translucency (yes / no)

333 - Percussion test (positive/negative)

334 - Apical pressure point (yes / no)

335 - Fistula (yes / no)

336 For the WO SF system a significantly shorter duration resulted in comparison to the MF systems

337 (121 sec; SD 37.40; $\mathrm{p}=0.01)$. The adjusted reduction in required preparation time was $32.8 \%$

338 with the SF-System.

339 The root canal preparation with the WaveOne System produces the same results regarding

340 reduction of patients' endodontic related pain and oral health related quality of life, but the

341 preparation speed per root canal is faster. 


\section{Discussion}

343 Our study showed that root canal treatment with MFs as well as with the SF WaveOne System

344 reduced the patients' endodontic related pain and improved oral health related quality of life

345 without statistically significant differences under conditions of general dental practice. The root

346 canal preparation with the SF system was faster.

\section{Measuring patients' endodontic pain and oral-health-related quality of life}

348 Pain intensity can be measured with various methods, e.g. the Visual Analog Scale (VAS), the

349 Numerical Rating Scale (NRS) or the Verbal (Categorical) Rating Scale (VRS). The VRS is an easy-to-apply measuring method, but forces the study subjects to select a wording which may not represent an adequate description of the pain they feel. Moreover, the VRS depends on a clear and unequivocal understanding of the language (Turk 2011). The NRS and VAS are uncomplicated measuring methods for the pain felt and both show good evidence of construct validation (Turk 2011). In the present study, the VAS was selected because it offers a large number of scores. This makes the VAS more sensitive to changes in the pain intensity felt than other scales offering fewer reply categories (Turk 2011). In addition, the VAS is widely used in

357 the endodontic literature (King et al. 2012; Martin-Gonzalez et al. 2012; Pak 2012; Udoye \&

358 Jafarzadeh 2011). The limitation to one scale is both feasible and adequate (Attar et al. 2008).

359 Pain assessment alone gives no information about the patients' oral-health-related quality of life which represents a patient-relevant outcome (Pfaff et al. 2009). The only validated German-

361 language measuring instrument for the oral-health-related quality of life is the OHIP (John et al. 362 2003). To limit the questionnaire to a practicable length, the OHIP-G-14 was used in our study 363 (John et al. 2004). In 2011, when the study was planned, there existed two endodontic studies 
364 which chose the OHIP-14 questionnaire for endodontic issues (Dugas et al. 2002; Gatten et al.

365 2011).

366

367

368

369

370

371

372

373

374

375

376

377

378

379

380

381

382

383

384

385

Description of the results

In the present study, we compared two clinical short-term outcome parameters of two basic methods of root canal preparation.

We defined the most important patient-relevant outcomes as reduction of pain by endodontic therapy and the improvement of oral-health-related quality of life. When we were planning this study in 2011, shortly after the introduction of reciprocating SF endodontic instruments (WaveOne and Reciproc), there was no information about the clinical performance of these instruments. The new system should have at least a similar or an enhanced clinical outcome compared to the conventional (MF) systems. This is an important condition when a new technology is introduced. Moreover, we expected greater speed and thus greater efficiency of the SF System as a relevant result. As far as the authors know, no studies had been made that compared the clinical outcome of MF and SF systems at the time of the study planning in 2011.

The reduction of pain and the improvement of oral health related quality of life as a result of endodontic treatment were not different in the two experimental groups (MF and SF) in the second week after treatment. Both methods were equally effective in reducing endodontic pain. The mean pain intensity of about 43.2 (SD 32.2) VAS before root canal treatment and about 9.5 (SD 19.0) VAS after treatment agrees with the results obtained by other researchers who investigated pain reduction after endodontic therapy (Ehrmann et al. 2003; Pak \& White 2011). A review found that pain levels before endodontic therapy of 54 VAS and a standard deviation of 24 VAS are a common average in endodontic studies and decrease to less than 10 VAS on 
386

387

388

389

390

391

392

393

394

395

396

397

398

399

400

401

402

403

404

405

406

407

408

average within 7 days (Ehrmann et al. 2003; Pak \& White 2011). Also Ehrmann et al. (2003)

found very similar values to those in our study (44.4 (SD 26.9) VAS). The mean pain measured 4 days after endodontic therapy decreased to 7.5 (SD 15.5) VAS. The mean pain reduction of 36.9 (SD 29.0) VAS was very similar to the values in our study. The improvement of the OHIP-14 with mean scores of 12.8 (SD 10.6) before therapy found in our study are very comparable to another study where a mean OHIP-14 score of 15.4 (SD 10.5) was found before endodontic treatment (Liu et al. 2014). Also other studies report that endodontic treatment leads to an improvement of the oral-health-related quality of life (Dugas et al. 2002; Hamasha \& Hatiwsh 2013). This finding was confirmed by our study.

Recently a couple of randomized controlled trials (RCT) have been published, that evaluated the pain reduction and/or the improvement in quality of life of single file systems (Kherlakian et al. 2016; Pasqualini et al. 2015; Relvas et al. 2015). In the first RCT (Kherlakian et al. 2016) two SF reciprocating systems (Reciproc (VDW, Munich, Germany) and WaveOne (Dentsply)) and one MF system (ProTaper Next (Dentsply)) were compared. Only asymptomatic vital teeth were treated with the different systems. Therefore patients did not have pain before treatment. Also after treatment, pain rates on a categorized VAS 100 score were also very low and showed no significant differences between the systems. The second RCT (Relvas et al. 2015) compared one reciprocating SF system (Reciproc (VDW, Munich, Germany) with a MF system (ProTaper (Dentsply)). Only asymptomatic teeth with apical periodontitis were included in the trial. Therefore patients were pain-free before treatment. Pain measurement was not performed with the VAS. Therefore results can be hardly compared with our study. The different instrument systems showed no statistically significant differences in postoperative pain scores after $24 \mathrm{~h}$ and 72h. The third RCT (Pasqualini et al. 2015) investigated the ProTaper MF and the WaveOne SF 
409 system. Compared were primary root canal treatments of every clinical condition (symptomatic, 410 asymptomatic, vital and non-vital cases). Mean pain on VAS was 35.2 for SF before treatment 411 and 24.6 for MF decreasing to very low rates of 1.3 (SF) and 0.9 (MF) after seven days. This is

412 different to our study, where the mean pain scores were higher before treatment, but more equal.

413 And also our mean pain scores in the second week after treatment were higher than the score

414 found in the above mentioned study. If this can be interpreted as an effectiveness gap regarding 415 the success of these instruments in general dental practice compared to specialized care providers 416 remains unclear, because our initial VAS scores were higher and therefore perhaps naturally 417 need a longer time period to drop to low scores. Recently our research group published a smaller, 418 but very similar study comparing hand instrumentation with Reciproc for root canal preparation 419 under conditions of general dental practice (Bartols et al. 2016). The mean pain score before root 420 canal treatment with hand instruments was 43.6 (SD 30.7) VAS and with Reciproc it was 41.2 421 (SD 27.7) VAS, which is perfectly comparable with the initial values of the present study where 422 the initial VAS scores were 42.3 (SD 32.6) VAS for MF and 43.9 (SD 32.0) VAS for SF. Within 423 the same period of time the scores decreased in all four groups to values in the range between 9.3 424 and 11.5 (with SDs of 16.5-19.2) VAS with therefore only minimal differences. Also regarding 425 OHRQoL the OHIP-G-14 scores of all four groups show only minimal differences before 426 treatment and before completion of therapy (hand instruments 9.2 (SD 9.6) decreasing to 3.4 (SD 427 5.4), Reciproc 10.4 (SD 9.6) decreasing to 3.5 (SD 6.1), MF 12.5 (SD 10.6) decreasing to 3.6 428 (SD 5.1) and SF WaveOne 13.0 (SD 10.8) decreasing to 4.6 (SD 6.5). Therefore it can be 429 concluded, that all four techniques investigated show the same clinical outcome regarding pain 430 reduction and improvement in OHRQoL under routine care conditions. 
431 As the main outcome parameter was the reduction of endodontic pain after treatment, the

432 different root canal preparation techniques and their influence on postoperative pain has to be

433 considered. Recently it was demonstrated that different root canal preparation techniques lead to

434 the expression of different levels of inflammatory neuropeptides in the periapical periodontal 435 ligament linked with the possible emergence of symptomatic apical periodontitis (Caviedes436 Bucheli et al. 2013). It is believed that this is connected to the different amounts of extruded 437 debris beyond the apical foramen (Caviedes-Bucheli et al. 2016). Since nearly all root canal 438 instrumentation techniques including hand instrumentation as well as engine driven instruments 439 lead to apical extrusion of debris (Al-Omari \& Dummer 1995; Bürklein \& Schäfer 2012; Capar 440 et al. 2014; De-Deus et al. 2010) in most cases there will be an inflammatory response to a 441 certain extent. In an in-vitro studies reciprocating instruments extruded more debris than rotary 442 instruments (Bürklein \& Schäfer 2012) with Reciproc producing most debris while another in443 vitro studies found Reciproc to produce significantly less extruded debris compared to rotary 444 techniques (Kocak et al. 2013). The only clinical studies measuring the expression of 445 inflammatory neuropeptides in the periodontal ligament found that the instrument design of 446 engine driven root canal instruments has a greater impact on expression of neuropeptides than 447 the instrumentation technique (Caviedes-Bucheli et al. 2016). Because of this contradictory data 448 situation and the limited knowledge if the amount of expressed neuropeptides can be directly 449 correlated to the perceived pain it remains unclear if there is an impact on the postoperative pain 450 levels of patients after root canal treatment. In our study the preoperative levels of pain, their 451 improvement and the postoperative VAS pain levels were very similar and very much

452 comparable to our previously published study (Bartols et al. 2016). Therefore in the 
453 heterogeneous situation of clinical cases, the impact of the root canal preparation systems used

454 seems to be limited regarding postoperative pain relief.

455 A significant difference was found in the speed of root canal preparation. The preparation time 456 required when using WO instruments was on average 92 seconds shorter than the time required 457 with MF systems. This time is probably saved because the WO system does not require any 458 instrument changes. As changing instruments cannot be avoided with MF systems, the time 459 needed for it was included in the time measurement. An in-vitro study reported that root canal 460 preparation with WaveOne instruments in contrast to MF systems is about 100 seconds faster 461 (Bürklein et al. 2012). This time benefit per canal was also observed in our study. In both study 462 designs the instrumentation time included instrument changes, cleaning of instruments and 463 irrigation of the root canal. Therefore results are comparable. Thus, there is nearly no 464 effectiveness gap of the method. This was not necessarily to be expected as unlike root canal 465 preparation in the laboratory the preparation in the patient's mouth is more complicated due to 466 patient-related factors, such as mouth opening, restlessness of the patient etc. The time saved in 467 canal preparation can be beneficially reinvested in additional root canal disinfection (van der 468 Sluis et al. 2009).

469 In general, the endodontic literature proves that pain that existed before endodontic therapy will

470 be reduced by root canal therapy (Ehrmann et al. 2003; Genet et al. 1986; Pak \& White 2011).

471 Comparative studies on endodontic pain have so far mainly compared different types of pain 472 medication (Attar et al. 2008; Ryan et al. 2008), different types of root canal dressings (Ehrmann 473 et al. 2003; Torabinejad et al. 1994) and differences between single-visit vs. multiple-visit 474 treatment (Prashanth et al. 2011; Su et al. 2011). For single- versus multiple-visit treatment, 475 studies found no differences for one week postoperative pain levels (Figini et al. 2008; Prashanth 
476 et al. 2011). This suits our results, because we also did not find differences in our analyses

477 regarding single- versus multiple-visit treatments regarding pain reduction. For OHRQoL there

478 was a difference in improvement of OHIP-14 scores between single- and multiple-visit

479 treatments. But as the initial OHIP-14 scores were significantly lower in the single-visit group

480 than the initial scores in the multiple-visit group, we conclude that the PIs primarily treated

481 "safe" cases with low initial OHIP-14 scores as single-visit.

482 Clinical trials comparing pain after root canal preparation with different instrument systems are 483 rare (Gambarini et al. 2013; Kherlakian et al. 2016; Pasqualini et al. 2015; Relvas et al. 2015)

484 and have mostly low case numbers ( $\mathrm{N}=30-70$ per experimental group). The authors do not know

485 of any large-scale clinical comparative studies with high case numbers reliably reflecting the

486 dental practice reality. Research in practice networks offers an environment which allows to

487 generate case numbers high enough for clinical trials (Nixdorf et al. 2012). In this way new

488 research opportunities are created that can also be applied to other issues of endodontics or other

489 fields of dentistry.

490 All three outcome parameters reflect patient relevant short term success criteria, that are not 491 necessarily connected to the long term success of the treatments performed. To the knowledge of 492 the authors until now there is only one study that investigated also the long term success of 493 technological change from stainless steel instrumentation to rotary instrumentation in a general 494 dental practitioner situation in the Swedish Public Dental Service (Koch et al. 2015). While tooth 495 survival was higher in teeth treated post-education with rotary instruments there was no 496 improvement in periapical health. Only surrogate parameters like the technical quality of the 497 treatments improved. Studies investigating the long term outcome after technological change to 498 reciprocating technique in endodontics are not known to the authors. Therefore further research 
499 regarding long term results of reciprocating techniques in general dental practice is needed. Study

500 design and feasibility

501 Generally this study was planned as a health services research study. Therefore it was never

502 intended to compare two treatment groups in a classical clinical trial setting. We wanted to

503 investigate the effects of technological change in endodontic treatment in general dental practices

504 and chose therefore a study design in a timeline sequence and not a study design with parallel

505 treatments groups. We accompanied the technological change in endodontic treatment methods

506 in everyday dental practice to uncover possible "shortcomings" or effectiveness gaps by

507 structured observation, which were basically not found for short-term outcomes as pain reduction

508 and improvement of OHRQoL.

509 In the present study, the number of recruited patients agreed with the initial case number

510 planning. The planning therefore seemed to be based on realistic assumptions. The return rates of

511 the collected study data and questionnaires were high and the patients were adequately followed

512 up. Judged by these requirements, research can be conducted in dental practices in an adequate

513 way. (Kohout et al. 2015)

514 Ten GDPs agreed to participate in the study as PIs. This exactly equaled the number underlying

515 the power analysis. The recruitment of the minimum number of required GDPs poses the risk

516 that the case numbers aimed at cannot be reached. As studies of this type are rare in endodontics,

517 there are no broadly-based typical figures available on the experience regarding the recruitment

518 of PIs. There is only one study pursuing a similar approach by observing the results obtained in

519 dental practices (Nixdorf et al. 2012). That study was designed as an observational study to

520 measure pain and burden connected with initial orthograde root canal treatment. 62 GDPs 
521 participated in the study, whereas 48 had been aimed for in case number planning. This

522 corresponds to an over-recruitment rate of $29 \%$ (Nixdorf et al. 2012).

523 Contrary to that study (Nixdorf et al. 2012), the present study takes an approach to compare

524 different treatment methods, which makes considerably higher demands on the participating

525 GDPs. The GDPs had to undergo training to learn how to prepare the root canals with the SF

526 WaveOne instruments and, at the same time, they had to care for two therapeutic groups and to

527 recruit themselves the patients for each. The GDPs did not get any financial support. As an

528 incentive they were offered a payment of EUR 5 for every evaluable/analyzable case which,

529 however, most colleagues did not take. The training for the use of WaveOne instruments was

530 provided free of charge to the GDPs. In addition, in the second study phase Dentsply Maillefer

531 (Ballaigues, Switzerland) made available the required WaveOne files free of charge and loaned

532 the GDPs the Wave-One motors. In view of the fact that the literature describes serious

533 resentments of German physicians against practice-based clinical trials (Hummers-Pradier et al.

534 2012; Hummers-Pradier et al. 2008; KZBV 2011), it is a special success to recruit 10 GDPs.

535 Moreover a recently published similar study of our research group showed, that 3 of 9 PIs could

536 not cope with the organizational demands of a study like this and could not contribute any cases

537 for evaluation (Bartols et al. 2016).

538 The participating GDPs documented treatments that were required anyway. The practice routine

539 had to be changed for the documentation requirements of the study, but the organizational work

540 with the study participants was mainly delegated to the assistant dental staff. This certainly is one

541 reason for the good feasibility of the study. Moreover, there were no special demands on the

542 patients, so that their willingness to participate in the study was very high. The GDPs screened

543668 patients and actually enrolled 599 in the study so that on average every GDP screened about 
5441.1 patients to include one in the study. Compared with the study of Nixdorf et al. (2012) who

545 screened 1.5 patients for each subject included in the study, this is a high rate of inclusion and

546 shows the patients' great willingness to participate in a clinical trial of the extent described here.

547 Altogether 599 participants were recruited, whereas 560 would have been needed. This is an

548 over-recruitment of not quite $7 \%$, so that, on average, the case number aimed for was reached.

549 However, the individual case numbers differed very much (Table 1).

550 The two-phase study design split into separate periods increased the GDPs' willingness to

551 participate in the clinical study because it limited the organizational effort for the study.

552 Although this means that the present study was not based on randomization, generally considered

553 the optimum study design (Friedman et al. 2010; Hulley 2013), the clear time split of the study

554 groups prevented randomization errors and selection bias at the level of the participating dental

555 practices in the sense of manipulating the patient randomization to each of the study groups and

556 was also used in another study investigating endodontic technological change in general dental

557 practice (Koch et al. 2015). The consecutive sample used in the present study also counteracted

558 the volunteer bias (volunteerism) (Hulley 2013). Additionally the broad inclusion criteria for the

559 participating patients made recruitment feasible for the PIs and reflects in this way the conditions

560 of everyday general dental practice.

\section{Conclusion}

562 Concerning the reduction of endodontic pain and improvement of oral health related quality of

563 life, the WaveOne SF system shows no statistical difference to MF systems under the conditions

564 of general dental practice. The speed of preparation of root canals appears to be higher with the

565 WaveOne SF instruments. 


\section{Acknowledgements}

567 The authors would like to thank all the participating dental practices and all patients for their 568 cooperation. We are deeply grateful for the opportunity to conduct this study.

\section{References}

570 Al-Omari MA, and Dummer PM. 1995. Canal blockage and debris extrusion with eight $571 \quad$ preparation techniques. J Endod 21:154-158.

572 Attar S, Bowles WR, Baisden MK, Hodges JS, and McClanahan SB. 2008. Evaluation of pretreatment analgesia and endodontic treatment for postoperative endodontic pain. $J$

\section{5}

Bartols A, Reutter CA, Robra B-P, and Walther W. 2016. Reciproc vs. hand instrumentation in Endod 34:652-655. 10.1016/j.joen.2008.02.017

577

578

579

580

581 dental practice: a study in routine care. PeerJ 4:e2182. 10.7717/peerj.2182

Bergenholtz G, Axelsson S, Davidson T, Frisk F, Hakeberg M, Helgesson G, Håkanson K, Kedebring T, Kvist T, Lindblom J, Mejàre I, Norlund A, Petersson A, Portenier I, Sandberg H, and Tranæus S. 2012. Methods of Diagnosis and Treatment in Endodontics. Swedish Council on Health Technology Assessment.

Bürklein S, Benten S, and Schäfer E. 2013. Shaping ability of different single-file systems in severely curved root canals of extracted teeth. Int Endod J 46:590-597. 10.1111/iej.12037

Bürklein S, Hinschitza K, Dammaschke T, and Schäfer E. 2012. Shaping ability and cleaning effectiveness of two single-file systems in severely curved root canals of extracted teeth: Reciproc and WaveOne versus Mtwo and ProTaper. International Endodontic Journal 45:449-461. 10.1111/j.1365-2591.2011.01996.x 
587 Bürklein S, and Schäfer E. 2012. Apically extruded debris with reciprocating single-file and full-

588

589

590

591

592

593

594

595

596

597

598

599

600

601

602

603

604

605

606

607

608

609 sequence rotary instrumentation systems. J Endod 38:850-852. 10.1016/j.joen.2012.02.017

Campbell MK, Thomson S, Ramsay CR, MacLennan GS, and Grimshaw JM. 2004. Sample size calculator for cluster randomized trials. Computers in biology and medicine 34:113-125. $10.1016 / \mathrm{S} 0010-4825(03) 00039-8$

Capar ID, Arslan H, Akcay M, and Ertas H. 2014. An in vitro comparison of apically extruded debris and instrumentation times with ProTaper Universal, ProTaper Next, Twisted File Adaptive, and HyFlex instruments. J Endod 40:1638-1641. 10.1016/j.joen.2014.04.004

Caviedes-Bucheli J, Castellanos F, Vasquez N, Ulate E, and Munoz HR. 2016. The influence of two reciprocating single-file and two rotary-file systems on the apical extrusion of debris and its biological relationship with symptomatic apical periodontitis. A systematic review and meta-analysis. International Endodontic Journal 49:255-270. 10.1111/iej.12452

Caviedes-Bucheli J, Moreno JO, Carreno CP, Delgado R, Garcia DJ, Solano J, Diaz E, and Munoz HR. 2013. The effect of single-file reciprocating systems on Substance P and Calcitonin gene-related peptide expression in human periodontal ligament. Int Endod $J$ 46:419-426. 10.1111/iej.12005

De-Deus G, Brandao MC, Barino B, Di Giorgi K, Fidel RA, and Luna AS. 2010. Assessment of apically extruded debris produced by the single-file ProTaper F2 technique under reciprocating movement. Oral Surg Oral Med Oral Pathol Oral Radiol Endod 110:390394. 10.1016/j.tripleo.2010.04.020

Donner A, and Klar N. 2000. Design and analysis of cluster randomization trials in health research. London 
610 New York, N.Y.: Arnold;

611 Co-published by the Oxford University Press.

612 Dugas NN, Lawrence HP, Teplitsky P, and Friedman S. 2002. Quality of life and satisfaction 613

614 outcomes of endodontic treatment. J Endod 28:819-827. 10.1097/00004770-20021200000007

615

616

617

618

619

620

621

622

623

624

625

626

627

628

629

630

631

Ehrmann EH, Messer HH, and Adams GG. 2003. The relationship of intracanal medicaments to postoperative pain in endodontics. International Endodontic Journal 36:868-875. 10.1111/j.1365-2591.2003.00735.x

Endodontology ESo. 2006. Quality guidelines for endodontic treatment: consensus report of the European Society of Endodontology. Int Endod J 39:921-930.

Figini L, Lodi G, Gorni F, and Gagliani M. 2008. Single versus multiple visits for endodontic treatment of permanent teeth: a Cochrane systematic review. J Endod 34:1041-1047. 10.1016/j.joen.2008.06.009

Fleming CH, Litaker MS, Alley LW, and Eleazer PD. 2010. Comparison of classic endodontic techniques versus contemporary techniques on endodontic treatment success. $J$ Endod 36:414-418. 10.1016/j.joen.2009.11.013

Friedman LM, Furberg CD, and DeMets DL. 2010. Fundamentals of Clinical Trials. 4. ed. New York, NY: Springer.

Gambarini G, Testarelli L, De Luca M, Milana V, Plotino G, Grande NM, Rubini AG, Al Sudani D, and Sannino G. 2013. The influence of three different instrumentation techniques on the incidence of postoperative pain after endodontic treatment. Annali di stomatologia $4: 152-155.10 .11138 /$ ads. 0152 
632 Gatten DL, Riedy CA, Hong SK, Johnson JD, and Cohenca N. 2011. Quality of life of 633 endodontically treated versus implant treated patients: a University-based qualitative 634 research study. J Endod 37:903-909. 10.1016/j.joen.2011.03.026

635 Genet JM, Wesselink PR, and Thoden van Velzen SK. 1986. The incidence of preoperative and 636 postoperative pain in endodontic therapy. Int Endod J 19:221-229.

637

638

639

640

641

642

643

644

645

646

647

648

649

650

651

652

653

654

Goldberg M, Dahan S, and Machtou P. 2012. Centering Ability and Influence of Experience When Using WaveOne Single-File Technique in Simulated Canals. Int J Dent 2012:206321. 10.1155/2012/206321

Hamasha AA, and Hatiwsh A. 2013. Quality of life and satisfaction of patients after nonsurgical primary root canal treatment provided by undergraduate students, graduate students and endodontic specialists. International Endodontic Journal. 10.1111/iej.12106

Hulley SB. 2013. Designing clinical research. Philadelphia: Wolters Kluwer/Lippincott Williams \& Wilkins.

Hülsmann M. 2013. Research that matters - canal preparation, retreatment and working length studies. International Endodontic Journal 46:293-295. 10.1111/iej.12063

Hülsmann M, and Schäfer E. 2005. "Good clinical practice": Die Wurzelkanalbehandlung. Stellungnahme der DGZ/DGZMK. Deutsche Zahnärztliche Zeitschrift 60:418-419.

Hummers-Pradier E, Bleidorn J, Schmiemann G, Joos S, Becker A, Altiner A, Chenot J-F, Scherer M, and Network' tGCTiGGP. 2012. General practice-based clinical trials in Germany - a problem analysis. Trials 13:205.

Hummers-Pradier E, Scheidt-Nave C, Martin H, Heinemann S, Kochen MM, and Himmel W. 2008. Simply no time? Barriers to GPs' participation in primary health care research. Family Practice 25:105-112. 10.1093/fampra/cmn015 
655 John MT, LeResche L, Koepsell TD, Hujoel P, Miglioretti DL, and Micheelis W. 2003. Oral 656 health-related quality of life in Germany. Eur J Oral Sci 111:483-491.

657 John MT, Micheelis W, and Biffar R. 2004. [Reference values in oral health-related quality of 658 life for the abbreviated version of the Oral Health Impact Profile]. Schweiz Monatsschr $659 \quad$ Zahnmed 114:784-791.

660 Kherlakian D, Cunha RS, Ehrhardt IC, Zuolo ML, Kishen A, and da Silveira Bueno CE. 2016. 661 Comparison of the Incidence of Postoperative Pain after Using 2 Reciprocating Systems

662 663 and a Continuous Rotary System: A Prospective Randomized Clinical Trial. J Endod 42:171-176. 10.1016/j.joen.2015.10.011

664

665

666

667

668

669

670

671

672

673

674

675

676

677

King JW, Bair E, Duggan D, Maixner W, and Khan AA. 2012. The relationship between resting arterial blood pressure and acute postoperative pain in endodontic patients. J Orofac Pain 26:321-327.

Kocak S, Kocak MM, Saglam BC, Turker SA, Sagsen B, and Er O. 2013. Apical extrusion of debris using self-adjusting file, reciprocating single-file, and 2 rotary instrumentation systems. J Endod 39:1278-1280. 10.1016/j.joen.2013.06.013

Koch M, Wolf E, Tegelberg A, and Petersson K. 2015. Effect of education intervention on the quality and long-term outcomes of root canal treatment in general practice. Int Endod J 48:680-689. 10.1111/iej.12367

Kohout GD, He J, Primus CM, Opperman LA, and Woodmansey KF. 2015. Comparison of Quick-Set and mineral trioxide aggregate root-end fillings for the regeneration of apical tissues in dogs. $J$ Endod 41:248-252. 10.1016/j.joen.2014.10.005

KZBV. 2011. Jahrbuch statistische Basisdaten zur vertragszahnärztlichen Versorgung ; einschließlich GOZ-Analyse. Köln: KZBV. 
678 Martin-Gonzalez J, Echevarria-Perez M, Sanchez-Dominguez B, Tarilonte-Delgado ML, 679 Castellanos-Cosano L, Lopez-Frias FJ, and Segura-Egea JJ. 2012. Influence of root canal 680 instrumentation and obturation techniques on intra-operative pain during endodontic 681 therapy. Med Oral Patol Oral Cir Bucal 17:e912-918.

682 Ng YL, Mann V, Rahbaran S, Lewsey J, and Gulabivala K. 2007. Outcome of primary root canal 683 684 685 686 treatment: systematic review of the literature - part 1. Effects of study characteristics on probability of success. International Endodontic Journal 40:921-939. 10.1111/j.1365-

Pak JG. 2012. Patient-Based Endodontic Outcomes, Systematic Reviews of Pathology and Pain 691 Prevalences. 2591.2007.01322.x

Nixdorf DR, Law AS, Look JO, Rindal DB, Durand EU, Kang W, Agee BS, Fellows JL, Gordan VV, and Gilbert GH. 2012. Large-scale clinical endodontic research in the national dental practice-based research network: study overview and methods. J Endod 38:1470-1478. 10.1016/j.joen.2012.08.002

694 695

696

697

698

699

700

Pak JG, and White SN. 2011. Pain prevalence and severity before, during, and after root canal treatment: a systematic review. J Endod 37:429-438. 10.1016/j.joen.2010.12.016

Pasqualini D, Corbella S, Alovisi M, Taschieri S, Del Fabbro M, Migliaretti G, Carpegna GC, Scotti N, and Berutti E. 2015. Postoperative quality of life following single-visit root canal treatment performed by rotary or reciprocating instrumentation: a randomized clinical trial. Int Endod J. 10.1111/iej.12563

Peters LB, and Wesselink PR. 2002. Periapical healing of endodontically treated teeth in one and two visits obturated in the presence or absence of detectable microorganisms. Int Endod J 35:660-667. 
701 Pettiette MT, Delano EO, and Trope M. 2001. Evaluation of success rate of endodontic treatment 702 performed by students with stainless-steel K-files and nickel-titanium hand files. $J$ Endod

703

704

705

706

707

708

709

710

711

712

713

714

715

716

717

718

719

720

721 27:124-127.

Pfaff H, Glaeske G, Neugebauer EA, and Schrappe M. 2009. [Memorandum III: "Methods for Health Services Research" (Part 1)]. Gesundheitswesen 71:505-510. 10.1055/s-00291234066

Pfaff H, Nellessen-Martens G, and Scriba PC. 2011. Lehrbuch Versorgungsforschung Systematik - Methodik-Anwendung ; mit 19 Tabellen ; [input, throughput, output, outcome]. Stuttgart: Schattauer.

Prashanth MB, Tavane PN, Abraham S, and Chacko L. 2011. Comparative evaluation of pain, tenderness and swelling followed by radiographic evaluation of periapical changes at various intervals of time following single and multiple visit endodontic therapy: an in vivo study. J Contemp Dent Pract 12:187-191.

Relvas JB, Bastos MM, Marques AA, Garrido AD, and Sponchiado EC, Jr. 2015. Assessment of postoperative pain after reciprocating or rotary NiTi instrumentation of root canals: a randomized, controlled clinical trial. Clin Oral Investig. 10.1007/s00784-015-1692-0

Ryan JL, Jureidini B, Hodges JS, Baisden M, Swift JQ, and Bowles WR. 2008. Gender differences in analgesia for endodontic pain. $J$ Endod 34:552-556. 10.1016/j.joen.2008.01.021

Schäfer E, Schulz-Bongert U, and Tulus G. 2004. Comparison of hand stainless steel and nickel titanium rotary instrumentation: a clinical study. Journal of endodontics 30:432-435. 
722 Singer JD. 1998. Using SAS PROC MIXED to Fit Multilevel Models, Hierarchical Models, and

723

724

725

726

727

728

729

730

731

732

733

734

735

736

737

738

739

740

741

742

743

744

Individual Growth Models. Journal of Educational and Behavioral Statistics 23:323-355.

$10.3102 / 10769986023004323$

Slade GD. 1997. Derivation and validation of a short-form oral health impact profile. Community Dent Oral Epidemiol 25:284-290.

$\mathrm{Su}$ Y, Wang C, and Ye L. 2011. Healing rate and post-obturation pain of single- versus multiplevisit endodontic treatment for infected root canals: a systematic review. J Endod 37:125132. 10.1016/j.joen.2010.09.005

Torabinejad M, Dorn SO, Eleazer PD, Frankson M, Jouhari B, Mullin RK, and Soluti A. 1994. Effectiveness of various medications on postoperative pain following root canal obturation. J Endod 20:427-431. 10.1016/s0099-2399(06)80031-2

Turk DC. 2011. Handbook of pain assessment. New York [u.a.]: Guilford Press.

Udoye CI, and Jafarzadeh H. 2011. Pain during root canal treatment: an investigation of patient modifying factors. J Contemp Dent Pract 12:301-304.

van der Sluis L, Wu MK, and Wesselink P. 2009. Comparison of 2 flushing methods used during passive ultrasonic irrigation of the root canal. Quintessence Int 40:875-879.

Weiger R, Rosendahl R, and Lost C. 2000. Influence of calcium hydroxide intracanal dressings on the prognosis of teeth with endodontically induced periapical lesions. Int Endod J $33: 219-226$.

Yared G. 2008. Canal preparation using only one Ni-Ti rotary instrument: preliminary observations. International Endodontic Journal 41:339-344. 10.1111/j.13652591.2007.01351.x 


\section{Table $\mathbf{1}$ (on next page)}

Number of patients recruited by practitioner-investigator (P-I) and study group distribution 
1 Table 1 Number of patients recruited by practitioner-investigator $(P-I)$ and study group distribution

\begin{tabular}{crrrrrrrr}
\hline P-I ID & \multicolumn{9}{c}{ Instrument type } \\
& \multicolumn{9}{c}{ MF } & Target & Actual & SF & Target & Actual & Target & Actual \\
1 & BioRaCe & 28 & 28 & WaveOne & 28 & 28 & 56 & 56 \\
2 & RaCe & 28 & 45 & WaveOne & 28 & 56 & 56 & 101 \\
3 & BioRaCe & 28 & 30 & WaveOne & 28 & 23 & 56 & 53 \\
4 & BioRaCe & 28 & 22 & WaveOne & 28 & 23 & 56 & 45 \\
5 & Alpha Kite & 28 & 38 & WaveOne & 28 & 32 & 56 & 70 \\
6 & BioRaCe & 28 & 26 & WaveOne & 28 & 20 & 56 & 46 \\
7 & Mity Roto Files & 28 & 49 & WaveOne & 28 & 95 & 56 & 144 \\
8 & BioRaCe & 28 & 15 & WaveOne & 28 & 4 & 56 & 19 \\
9 & BioRaCe & 28 & 10 & WaveOne & 28 & 17 & 56 & 27 \\
10 & BioRaCe & 28 & 17 & WaveOne & 28 & 21 & 56 & 38 \\
\hline Total N & & 280 & $\mathbf{2 8 0}$ & & 280 & $\mathbf{3 1 9}$ & 560 & $\mathbf{5 9 9}$ \\
\hline
\end{tabular}

$2 \mathrm{MF}=$ multiple-file system, $\mathrm{SF}=$ single-file system (WaveOne) 


\section{Table 2 (on next page)}

Table 2 


\begin{tabular}{|c|c|c|c|c|c|c|c|c|c|c|c|c|c|}
\hline \multirow[b]{2}{*}{ Socio-demographic data of participants } & \multirow[b]{2}{*}{ Total } & \multicolumn{10}{|c|}{ Study center } & \multicolumn{2}{|c|}{ Study group } \\
\hline & & 1 & 2 & 3 & 4 & 5 & 6 & 7 & 8 & 9 & 10 & MF & SF \\
\hline \multicolumn{14}{|c|}{ Age $(y r)$} \\
\hline Mean & 50 & 52 & 46 & 55 & 53 & 49 & 52 & 47 & 59 & 49 & 61 & 50 & 50 \\
\hline SD & 16 & 15 & 13 & 17 & 16 & 13 & 17 & 16 & 16 & 15 & 14 & 15 & 16 \\
\hline Range & 18- & $20-83$ & $18-79$ & $19-88$ & $19-79$ & $23-85$ & $23-84$ & $19-80$ & $35-84$ & $19-74$ & $29-79$ & $18-85$ & $19-88$ \\
\hline Total $\mathbf{N}$ & $5 \hat{4} 8$ & 55 & 96 & 50 & 45 & 48 & 37 & 141 & 18 & 25 & 33 & 245 & 303 \\
\hline \multicolumn{14}{|l|}{ Gender (female) } \\
\hline$N(\%)$ & 269 & $28(51)$ & $42(42)$ & $35(66)$ & $16(36)$ & $23(43)$ & $21(48)$ & $68(48)$ & $7(37)$ & $16(59)$ & $13(37)$ & 126 & 143 \\
\hline Total $\mathbf{N}$ & 573 & 55 & 101 & 53 & 44 & 53 & 44 & 142 & 19 & 27 & 35 & 259 & 314 \\
\hline \multicolumn{14}{|l|}{ DMF-T } \\
\hline Mean & 12.0 & 15.5 & 7.7 & 16.2 & 17.0 & 7.8 & 11.4 & 9.3 & 17.4 & 10.0 & 20.7 & 12.0 & 12.0 \\
\hline Total $\mathbf{N}$ & 550 & 56 & 96 & 50 & 45 & 50 & 45 & 137 & 15 & 18 & 38 & 249 & 301 \\
\hline \multicolumn{14}{|l|}{ Highest education } \\
\hline Completed apprenticeship N (\%) & 241 & $31(58)$ & $40(40)$ & $15(41)$ & $22(65)$ & $17(35)$ & $15(37)$ & $57(43)$ & $13(87)$ & $20(74)$ & $11(34)$ & $95(41)$ & 146 \\
\hline Technical/Vocational school N & 97 & $10(19)$ & $12(12)$ & $12(32)$ & $7(21)$ & $13(27)$ & $9(22)$ & $20(15)$ & $1(7)$ & $4(15)$ & $9(28)$ & $52(22)$ & $45(\overline{1} 6)$ \\
\hline Ûniversity/College $\mathbf{N}(\%)$ & 92 & $7(13)$ & $33(33)$ & $1(3)$ & $0(0)$ & $10(21)$ & $12(29)$ & $17(13)$ & $1(7)$ & $0(0)$ & $11(34)$ & $47(20)$ & $45(16)$ \\
\hline Other N (\%) & 40 & $1(2)$ & $9(9)$ & $3(8)$ & $1(3)$ & $4(8)$ & $4(10)$ & $17(13)$ & $0(0)$ & $1(4)$ & $0(0)$ & $19(8)$ & $21(7)$ \\
\hline No $N(\%)$ & 51 & $4(8)$ & $6(6)$ & $6(16)$ & $4(12)$ & $4(8)$ & $1(2)$ & $23(17)$ & $0(0)$ & $2(7)$ & $1(3)$ & $21(9)$ & $30(11)$ \\
\hline Total $\mathbf{N}$ & 521 & 53 & 100 & 37 & 34 & 48 & 41 & 134 & 15 & 27 & 32 & 234 & 287 \\
\hline
\end{tabular}

MF multiple-file system SF single-file WaveOne 


\section{Table 3(on next page)}

Important socio-demographic characteristics and DMF-T of study participants by study center and study group 
Table 2 Important socio-demographic characteristics and DMF-T of study participants by study center and study group

\begin{tabular}{|c|c|c|c|c|c|c|c|c|c|c|c|c|c|}
\hline \multirow[b]{2}{*}{ Socio-demographic data of participants } & \multirow[b]{2}{*}{ Total } & \multicolumn{9}{|c|}{ Study center } & \multicolumn{3}{|c|}{ Study group } \\
\hline & & 1 & 2 & 3 & 4 & 5 & 6 & 7 & 8 & 9 & 10 & MF & SF \\
\hline \multicolumn{14}{|l|}{ Age (yr) } \\
\hline Mean & 50 & 52 & 46 & 55 & 53 & 49 & 52 & 47 & 59 & 49 & 61 & 50 & 50 \\
\hline SD & 16 & 15 & 13 & 17 & 16 & 13 & 17 & 16 & 16 & 15 & 14 & 15 & 16 \\
\hline Range & $18-88$ & $20-83$ & $18-79$ & $19-88$ & $19-79$ & $23-85$ & $23-84$ & $19-80$ & $35-84$ & $19-74$ & $29-79$ & $18-85$ & $19-88$ \\
\hline Total $\mathbf{N}$ & 548 & 55 & 96 & 50 & 45 & 48 & 37 & 141 & 18 & 25 & 33 & 245 & 303 \\
\hline \multicolumn{14}{|l|}{ Gender (female) } \\
\hline$N(\%)$ & 269 & $28(51)$ & $42(42)$ & $35(66)$ & $16(36)$ & $23(43)$ & $21(48)$ & $68(48)$ & $7(37)$ & $16(59)$ & $13(37)$ & $126(49)$ & $143(46)$ \\
\hline Total $N$ & 573 & 55 & 101 & 53 & 44 & 53 & 44 & 142 & 19 & 27 & 35 & 259 & 314 \\
\hline \multicolumn{14}{|l|}{ DMF-T } \\
\hline Mean & 12.0 & 15.5 & 7.7 & 16.2 & 17.0 & 7.8 & 11.4 & 9.3 & 17.4 & 10.0 & 20.7 & 12.0 & 12.0 \\
\hline Total $N$ & 550 & 56 & 96 & 50 & 45 & 50 & 45 & 137 & 15 & 18 & 38 & 249 & 301 \\
\hline \multicolumn{14}{|l|}{ Highest education } \\
\hline Completed apprenticeship N (\%) & 241 & $31(58)$ & $40(40)$ & $15(41)$ & $22(65)$ & $17(35)$ & $15(37)$ & $57(43)$ & $13(87)$ & $20(74)$ & $11(34)$ & $95(41)$ & $146(51)$ \\
\hline Technical/Nocational school N (\%) & 97 & $10(19)$ & $12(12)$ & $12(32)$ & $7(21)$ & $13(27)$ & $9(22)$ & $20(15)$ & $1(7)$ & $4(15)$ & $9(28)$ & $52(22)$ & $45(16)$ \\
\hline University/College N (\%) & 92 & $7(13)$ & $33(33)$ & $1(3)$ & $0(0)$ & $10(21)$ & $12(29)$ & $17(13)$ & $1(7)$ & $0(0)$ & $11(34)$ & $47(20)$ & $45(16)$ \\
\hline Other $\mathrm{N}(\%)$ & $40(8)$ & $1(2)$ & $9(9)$ & $3(8)$ & $1(3)$ & $4(8)$ & $4(10)$ & $17(13)$ & $0(0)$ & $1(4)$ & $0(0)$ & $19(8)$ & $21(7)$ \\
\hline No N (\%) & 51 & $4(8)$ & $6(6)$ & $6(16)$ & $4(12)$ & $4(8)$ & $1(2)$ & $23(17)$ & $0(0)$ & $2(7)$ & $1(3)$ & $21(9)$ & $30(11)$ \\
\hline Total $\mathbf{N}$ & 521 & 53 & 100 & 37 & 34 & 48 & 41 & 134 & 15 & 27 & 32 & 234 & 287 \\
\hline
\end{tabular}

MF multiple-file system SF single-file WaveOne 
Table 4 (on next page)

Questionnaire return rates for the enrolled participants 
1 Table 3 Questionnaire return rates for the enrolled participants

\begin{tabular}{|c|c|c|c|c|}
\hline Description & Timing & $\begin{array}{l}N \\
\text { (received) }\end{array}$ & $\begin{array}{l}N \\
\text { (expected) }\end{array}$ & $\%$ \\
\hline $\begin{array}{l}\text { Patient survey } \\
\text { demographic data } \\
\text { Pain and OHIP-14 }\end{array}$ & $\begin{array}{l}\text { before root } \\
\text { filling }\end{array}$ & 538 & 599 & 90 \\
\hline $\begin{array}{l}\text { survey before } \\
\text { treatment }\end{array}$ & $\begin{array}{l}\text { 1st } \\
\text { appointment }\end{array}$ & 565 & 599 & 94 \\
\hline $\begin{array}{l}\text { treatment } \\
\text { parameters }\end{array}$ & $\begin{array}{l}\text { all } \\
\text { appointments }\end{array}$ & 582 & 599 & 97 \\
\hline $\begin{array}{l}\text { Patient } 2 \text { weeks } \\
\text { follow-up survey }\end{array}$ & $\begin{array}{l}2 \text { weeks after } \\
\text { RCT }\end{array}$ & 518 & 599 & 86 \\
\hline
\end{tabular}

2 


\section{Table 5 (on next page)}

Table 4 
Table 4 Descriptive data of teeth treated by location, study center $(\mathrm{PI})$ and study group

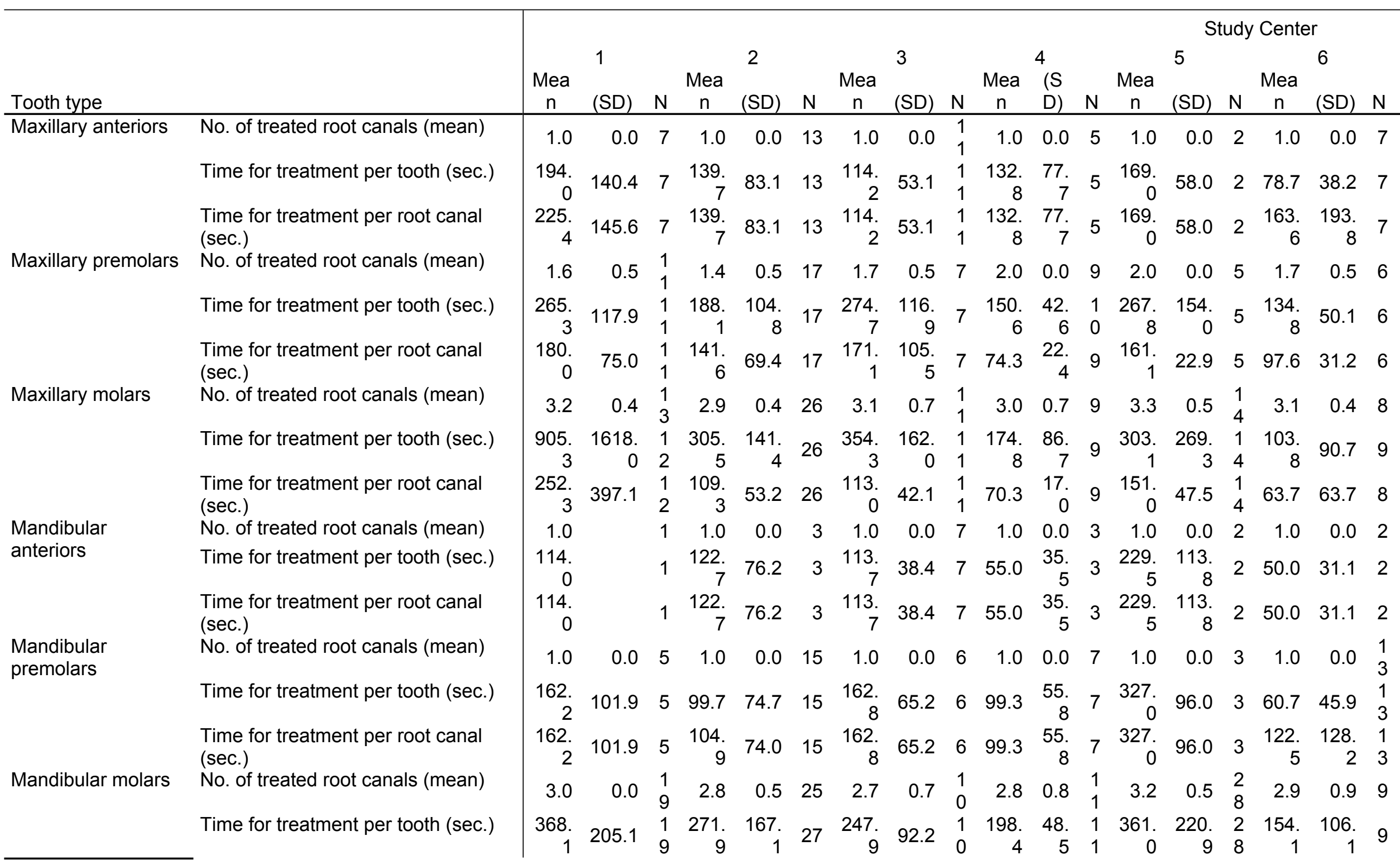




\begin{tabular}{|c|c|c|c|c|c|c|c|c|c|c|c|c|c|c|c|c|c|c|c|}
\hline & $\begin{array}{l}\text { Time for treatment per root canal } \\
\text { (sec.) }\end{array}$ & $\begin{array}{r}126 . \\
3 \\
\end{array}$ & 65.2 & $\begin{array}{l}1 \\
9 \\
\end{array}$ & 98.6 & 57.3 & 25 & 96.6 & 42.4 & $\begin{array}{l}1 \\
0\end{array}$ & 71.8 & $\begin{array}{r}13 . \\
1\end{array}$ & $\begin{array}{l}1 \\
1 \\
\end{array}$ & $\begin{array}{r}135 . \\
3\end{array}$ & 53.1 & $\begin{array}{l}2 \\
8 \\
\end{array}$ & 93.7 & 53.8 & 9 \\
\hline \multirow[t]{3}{*}{ Totals } & No. of treated root canals (mean) & 2.3 & 1.0 & $\begin{array}{l}5 \\
6\end{array}$ & 2.0 & 1.0 & 99 & 1.9 & 1.0 & $\begin{array}{l}5 \\
2\end{array}$ & 2.1 & 1.0 & $\begin{array}{l}4 \\
4\end{array}$ & 2.8 & 0.9 & $\begin{array}{l}5 \\
4\end{array}$ & 1.8 & 1.0 & $\begin{array}{l}4 \\
5\end{array}$ \\
\hline & Time for treatment per tooth (sec.) & $\begin{array}{r}419 . \\
2\end{array}$ & 790.9 & $\begin{array}{l}5 \\
5\end{array}$ & $\begin{array}{r}219 . \\
4\end{array}$ & $\begin{array}{r}147 . \\
8\end{array}$ & $\begin{array}{r}10 \\
1\end{array}$ & $\begin{array}{r}217 . \\
8\end{array}$ & $\begin{array}{r}134 . \\
9\end{array}$ & $\begin{array}{l}5 \\
2\end{array}$ & $\begin{array}{r}150 . \\
8\end{array}$ & $\begin{array}{r}71 . \\
2\end{array}$ & 5 & $\begin{array}{r}323 . \\
5\end{array}$ & $\begin{array}{r}217 . \\
9\end{array}$ & $\begin{array}{l}5 \\
4\end{array}$ & 99.3 & 76.8 & $\begin{array}{l}4 \\
6\end{array}$ \\
\hline & $\begin{array}{l}\text { Time for treatment per root canal } \\
\text { (sec.) }\end{array}$ & $\begin{array}{r}180 . \\
2\end{array}$ & 200.7 & $\begin{array}{l}5 \\
5\end{array}$ & $\begin{array}{r}115 . \\
9\end{array}$ & 66.0 & 99 & $\begin{array}{r}123 . \\
8\end{array}$ & 61.7 & $\begin{array}{l}5 \\
2\end{array}$ & 82.2 & $\begin{array}{r}41 . \\
3\end{array}$ & $\begin{array}{l}4 \\
4\end{array}$ & $\begin{array}{r}157 . \\
1\end{array}$ & 69.2 & $\begin{array}{l}5 \\
4\end{array}$ & $\begin{array}{r}106 . \\
1\end{array}$ & $\begin{array}{r}109 . \\
7\end{array}$ & $\begin{array}{l}4 \\
5\end{array}$ \\
\hline
\end{tabular}


Table 6(on next page)

Descriptive data of teeth treated by location, study center (PI) and study group 


\begin{tabular}{|c|c|c|c|c|c|c|c|c|c|c|c|c|c|c|c|c|c|c|c|c|c|c|c|c|c|c|c|c|c|c|c|c|c|c|c|c|c|c|c|c|}
\hline \multirow{3}{*}{ Tooth type } & & \multicolumn{30}{|c|}{ Study Center } & \multicolumn{9}{|c|}{ Study Group } \\
\hline & & \multirow[b]{2}{*}{ Mean } & \multicolumn{2}{|l|}{1} & \multicolumn{3}{|c|}{2} & \multicolumn{3}{|c|}{3} & \multicolumn{3}{|c|}{4} & \multicolumn{3}{|c|}{5} & \multicolumn{3}{|c|}{6} & \multicolumn{3}{|c|}{7} & \multicolumn{3}{|c|}{ 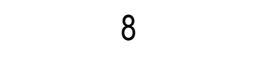 } & \multicolumn{3}{|c|}{9} & \multicolumn{3}{|c|}{10} & \multicolumn{3}{|c|}{ Multiple file } & \multicolumn{3}{|c|}{ Single file } & \multicolumn{3}{|c|}{ Total } \\
\hline & & & (SD) & $\mathrm{N}$ & Mean & (SD) & $\mathrm{N}$ & Mean & $(S D)$ & $\mathrm{N}$ & Mean & (SD) & $\mathrm{NM}$ & Mean & $(\mathrm{SD})$ & $\mathrm{NN}$ & Mean & $(\mathrm{SD})$ & $\mathrm{N}$ & Mean & $(S D)$ & $\mathrm{N}$ & Mean & $(\mathrm{SD})$ & $\mathrm{N} 1$ & Mean & $(\mathrm{SD})$ & $\mathrm{N}$ & Mean & (SD) & $\mathrm{N}$ & Mean & $(\mathrm{SD})$ & $\mathrm{N}$ & Mean & $(S D)$ & $\mathrm{N}$ & Mean & $(\mathrm{SD})$ & $\mathrm{N}$ \\
\hline Maxillary anteriors & No. of treated root canals (mean) & 1.0 & 0.0 & 7 & 1.0 & 0.0 & 13 & 1.0 & 0.0 & 11 & 1.0 & 0.0 & 5 & 1.0 & 0.0 & 2 & 1.0 & 0.0 & 7 & 1.1 & 0.3 & 23 & 1.0 & 0.0 & 2 & 1.0 & 0.0 & 2 & 1.0 & 0.0 & 0 & 1.0 & 0.0 & 37 & 1.1 & 0.3 & 43 & 1.0 & 0.2 & 280 \\
\hline & Time for treatment per tooth (sec.) & 194.0 & 140.4 & 7 & 139.7 & 83.1 & 13 & 114.2 & 53.1 & 11 & 132.8 & 77.7 & 51 & 169.0 & 58.0 & 2 & 78.7 & 38.2 & 7 & 155.0 & 201.6 & 22 & 50.0 & 14.1 & 2 & 93.0 & 52.3 & 2 & 1500.0 & 2342.3 & 8 & 252.9 & 227.7 & 37 & 293.4 & 41116.2 & 42 & 274.4 & 824.1 & 179 \\
\hline & 18 & 225.4 & 145.6 & 7 & 139.7 & 83.1 & 13 & 114.2 & 53.1 & 11 & 132.8 & 77.7 & 51 & 169.0 & 58.0 & 2 & 163.6 & 193.8 & 7 & 155.0 & 201.8 & 22 & 50.0 & 14.1 & 2 & 93.0 & 52.3 & 2 & 1500.0 & 2342.3 & 8 & 274.9 & 229.6 & 37 & 293.4 & 41116.2 & 42 & 284.7 & 824.2 & 279 \\
\hline laxillary premolars & $\mathrm{N}$ & 1.6 & 0.5 & 11 & 1.4 & 0.5 & 17 & 1.7 & 0.5 & 7 & 2.0 & 0.0 & 9 & 2.0 & 0.0 & 5 & 1.7 & 0.5 & 6 & 1.8 & 0.4 & 20 & 2.0 & 0.0 & 2 & 1.6 & 0.5 & 8 & 1.3 & 0.5 & 7 & 1.7 & 0.5 & 53 & 1.6 & 0.5 & 39 & 1.7 & 0.5 & $5 \quad 92$ \\
\hline & c.) & 265.3 & 117.9 & 11 & 188.1 & 104.8 & 17 & 274.7 & 116.9 & 7 & 150.6 & 42.6 & 102 & 267.8 & 154.0 & 5 & 134.8 & 50.1 & 6 & 296.6 & 273.8 & 19 & 87.5 & 17.7 & 2 & 115.1 & 128.4 & 8 & 950.0 & 435.0 & 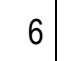 & 277.0 & 210.9 & 53 & 248.5 & $5 \quad 329.3$ & 38 & 265.1 & 265.5 & 591 \\
\hline & IIme io & 180.0 & 75.0 & 11 & 141.6 & 69.4 & 17 & 171.1 & 105.5 & 7 & 74.3 & 22.4 & 91 & 161.1 & 22.9 & 5 & 97.6 & 31.2 & 6 & 162.1 & 130.8 & 19 & 43.8 & 8.8 & 2 & 148.2 & 70.0 & 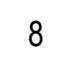 & 710.0 & 210.1 & 6 & 192.5 & 154.3 & 52 & 164.4 & $4 \quad 197.8$ & 38 & 180.7 & 173.5 & 590 \\
\hline Maxillary molars & No. of tr & 3.2 & 0.4 & 13 & 2.9 & 0.4 & 26 & 3.1 & 0.7 & 11 & 3.0 & 0.7 & 9 & 3.3 & 0.5 & 14 & 3.1 & 0.4 & 8 & 3.1 & 0.3 & 37 & 2.3 & 0.6 & 3 & 3.2 & 0.8 & 6 & 3.0 & 0.4 & 11 & 3.1 & 0.5 & 58 & 3.0 & 0.5 & 80 & 3.1 & 0.5 & 5138 \\
\hline & Time for treatment per tooth (sec.) & 905.3 & 1618.0 & 12 & 305.5 & 141.4 & 26 & 354.3 & 162.0 & 11 & 174.8 & 86.7 & 93 & 303.1 & 269.3 & 14 & 103.8 & 90.7 & 9 & 463.9 & 640.6 & 35 & 255.0 & 336.6 & 2 & 198.7 & 248.2 & 6 & 2100.0 & 523.8 & 11 & 795.1 & 744.8 & 57 & 322.7 & 757.9 & 78 & 522.1 & 785.3 & 3135 \\
\hline & IInie of & 252.3 & 397.1 & 12 & 109.3 & 53.2 & 26 & 113.0 & 42.1 & 11 & 70.3 & 17.0 & 91 & 151.0 & 47.5 & 14 & 63.7 & 63.7 & 8 & 164.9 & 226.7 & 35 & 86.4 & 110.2 & 2 & 133.7 & 46.9 & 6 & 700.9 & 141.5 & 11 & 273.1 & 246.1 & 57 & 120.3 & $3 \quad 204.8$ & 77 & 185.3 & 235.0 & 134 \\
\hline Mandibular anteriors & No. of tre & 1.0 & & 1 & 1.0 & 0.0 & 3 & 1.0 & 0.0 & 7 & 1.0 & 0.0 & 3 & 1.0 & 0.0 & 2 & 1.0 & 0.0 & 2 & 1.1 & 0.4 & 14 & 1.0 & 0.0 & 3 & 1.0 & 0.0 & 2 & 1.0 & 0.0 & 2 & 1.1 & 0.3 & 16 & 1.0 & 0.2 & 23 & 1.1 & 0.2 & 239 \\
\hline & Time for & 114.0 & & 1 & 122.7 & 76.2 & 3 & 113.7 & 38.4 & 7 & 55.0 & 35.5 & 32 & 229.5 & 113.8 & 2 & 50.0 & 31.1 & 2 & 271.1 & 268.9 & 14 & 45.0 & 5.0 & 3 & 172.0 & 1.4 & 2 & 1320.0 & 1018.2 & -1 & 276.1 & 239.8 & 16 & 195.6 & 421.0 & 23 & 228.6 & 356.2 & 239 \\
\hline & Time for & $\mid 114.0$ & & 1 & 122.7 & 76.2 & 3 & 113.7 & 38.4 & 7 & 55.0 & 35.5 & 32 & 229.5 & 113.8 & 2 & 50.0 & 31.1 & 2 & 249.3 & 259.6 & 14 & 45.0 & 5.0 & 3 & 172.0 & 1.4 & 2 & 1320.0 & 1018.2 & 2 & 259.2 & 229.2 & 16 & 194.1 & $1 \quad 421.5$ & 23 & 220.8 & 353.1 & $1 \quad 39$ \\
\hline Mandibular premolars & No. of tre & 1.0 & 0.0 & 5 & 1.0 & 0.0 & 15 & 1.0 & 0.0 & 6 & 1.0 & 0.0 & 7 & 1.0 & 0.0 & 3 & 1.0 & 0.0 & 13 & 1.1 & 0.3 & 28 & 1.0 & 0.0 & 2 & 1.0 & 0.0 & 6 & 1.0 & 0.0 & 1 & 1.0 & 0.2 & 35 & 1.0 & 0.2 & 52 & 1.0 & 0.2 & or \\
\hline & Time fo & 162.2 & 101.9 & 5 & 99.7 & 74.7 & 15 & 162.8 & 65.2 & 6 & 99.3 & 55.8 & 73 & 327.0 & 96.0 & 3 & 60.7 & 45.9 & 13 & 188.0 & 291.0 & 28 & 75.0 & 21.2 & 2 & 187.0 & 168.1 & 6 & 810.0 & 466.7 & 2 & 233.3 & 251.3 & 35 & 110.4 & $4 \quad 175.1$ & 52 & 159.8 & 216.4 & 87 \\
\hline & Ti & $\mid$\begin{tabular}{|l}
162.2 \\
\end{tabular} & 101.9 & 5 & 104.9 & 74.0 & 15 & 162.8 & 65.2 & 6 & 99.3 & 55.8 & 73 & 327.0 & 96.0 & 3 & 122.5 & 128.2 & 13 & 162.7 & 188.8 & 27 & 75.0 & 21.2 & 2 & 204.2 & 149.4 & 6 & 810.0 & 466.7 & 2 & 237.7 & 156.6 & 34 & 114.2 & 2174.4 & 52 & 163.0 & 177.4 & $\begin{array}{l}4 \\
\end{array}$ \\
\hline handibular molars & No. of tre & 3.0 & 0.0 & 19 & 2.8 & 0.5 & 25 & 2.7 & 0.7 & 10 & 2.8 & 0.8 & 11 & 3.2 & 0.5 & 28 & 2.9 & 0.9 & 9 & 3.3 & 0.5 & 20 & 2.8 & 0.4 & 6 & 2.7 & 0.6 & 3 & 3.3 & 0.5 & 8 & 3.0 & 0.6 & 61 & 3.0 & 0.6 & 78 & 3.0 & 0.6 & 39 \\
\hline & ent per tooth (sec.) & 368.1 & 205.1 & 19 & 271.9 & 167.1 & 27 & 247.9 & 92.2 & 10 & 198.4 & 48.5 & 113 & 361.0 & 220.9 & 28 & 154.1 & 106.1 & 9 & 589.8 & 824.3 & 19 & 113.2 & 103.1 & 6 & 181.0 & 158.2 & 3 & 2002.5 & 501.9 & 8 & 626.8 & 673.7 & 62 & 257.3 & $3 \quad 326.8$ & 78 & 421.0 & 540.6 & 140 \\
\hline & Time for treatment per root canal (sec.) & 126.3 & 65.2 & 19 & 98.6 & 57.3 & 25 & 96.6 & 42.4 & 10 & 71.8 & 13.1 & 111 & 135.3 & 53.1 & 28 & 93.7 & 53.8 & 9 & 181.9 & 263.5 & 19 & 53.9 & 22.2 & 5 & 108.6 & 33.4 & 3 & 635.6 & 168.4 & 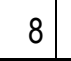 & 219.6 & 205.0 & 60 & 93.6 & 107.3 & 77 & 148.8 & 169.1 & 137 \\
\hline tals & No. of treated root canals (mean) & 2.3 & 1.0 & 56 & 2.0 & 1.0 & 99 & 1.9 & 1.0 & 52 & 2.1 & 1.0 & 44 & 2.8 & 0.9 & 54 & 1.8 & 1.0 & 45 & 2.0 & 1.0 & 142 & 1.9 & 0.9 & 18 & 1.9 & 1.0 & 21 & 2.1 & & 38 & 2.1 & 1.0 & 260 & 2.1 & 1.0 & 315 & 2.1 & 1.0 & 575 \\
\hline & & & 790.9 & 55 & 219.4 & 147.8 & 101 & 217.8 & 134.9 & 52 & 150.8 & 71.2 & 453 & 323.5 & 217.9 & 54 & 99.3 & 76.8 & 46 & 332.5 & 506.1 & 137 & 102.9 & 120.4 & 17 & 159.6 & 159.0 & & 1650.8 & 1214.3 & 37 & 464.6 & 554.9 & 260 & 8.4 & 608.0 & 311 & 346.8 & 593.8 & 571 \\
\hline & Time for treatment per root canal (sec.) & 0.2 & 200.7 & 55 & 115.9 & 66.0 & 99 & 123.8 & 61.7 & 52 & 82.2 & 41.3 & & 157.1 & 69.2 & 54 & 106.1 & 109.7 & 45 & 173.5 & 211.9 & 136 & 57.2 & 34.8 & & 150.7 & 86.3 & & 900.4 & 1114.8 & & 238.9 & 2 & 66 & 47.1 & $x^{2}$ & 309 & 188.7 & 5 & \\
\hline
\end{tabular}




\section{Figure 1 (on next page)}

Project plan

MF: Multiple-file system, SF: Single-file system WaveOne 


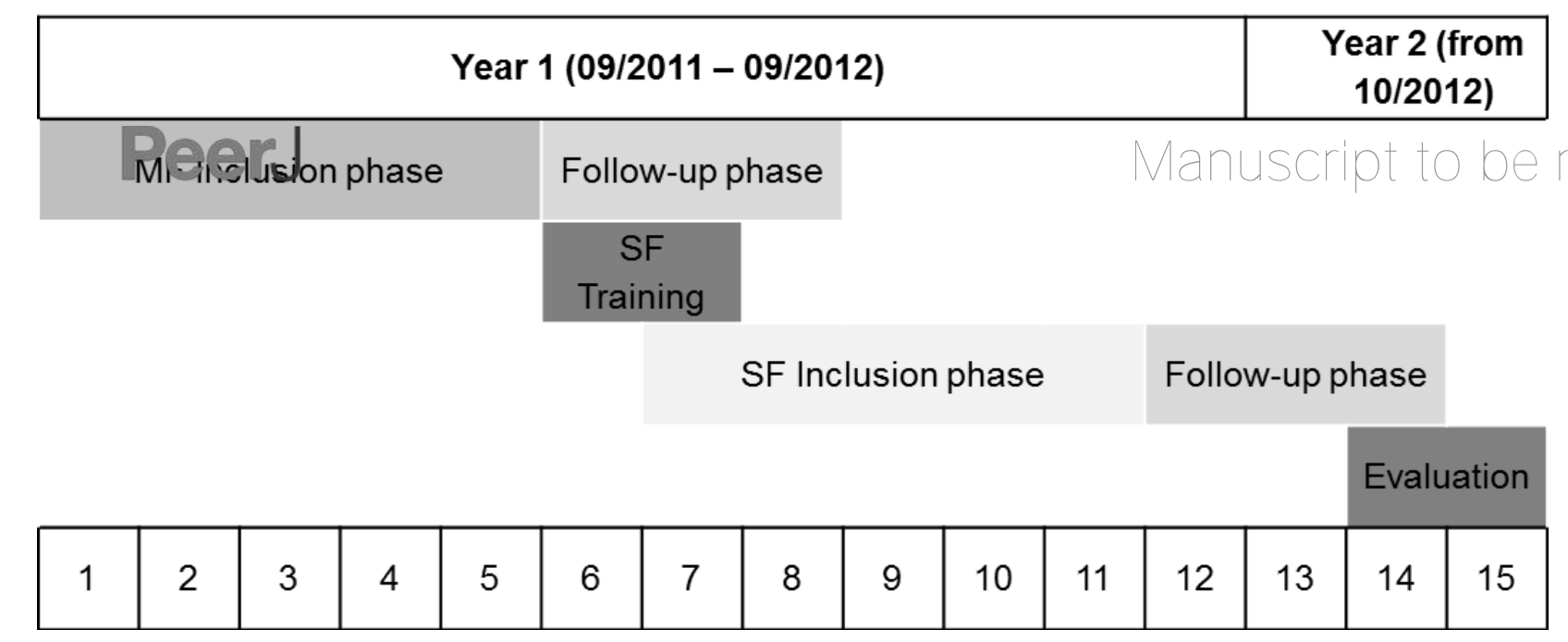




\section{Figure 2 (on next page)}

\section{Flow Diagram}




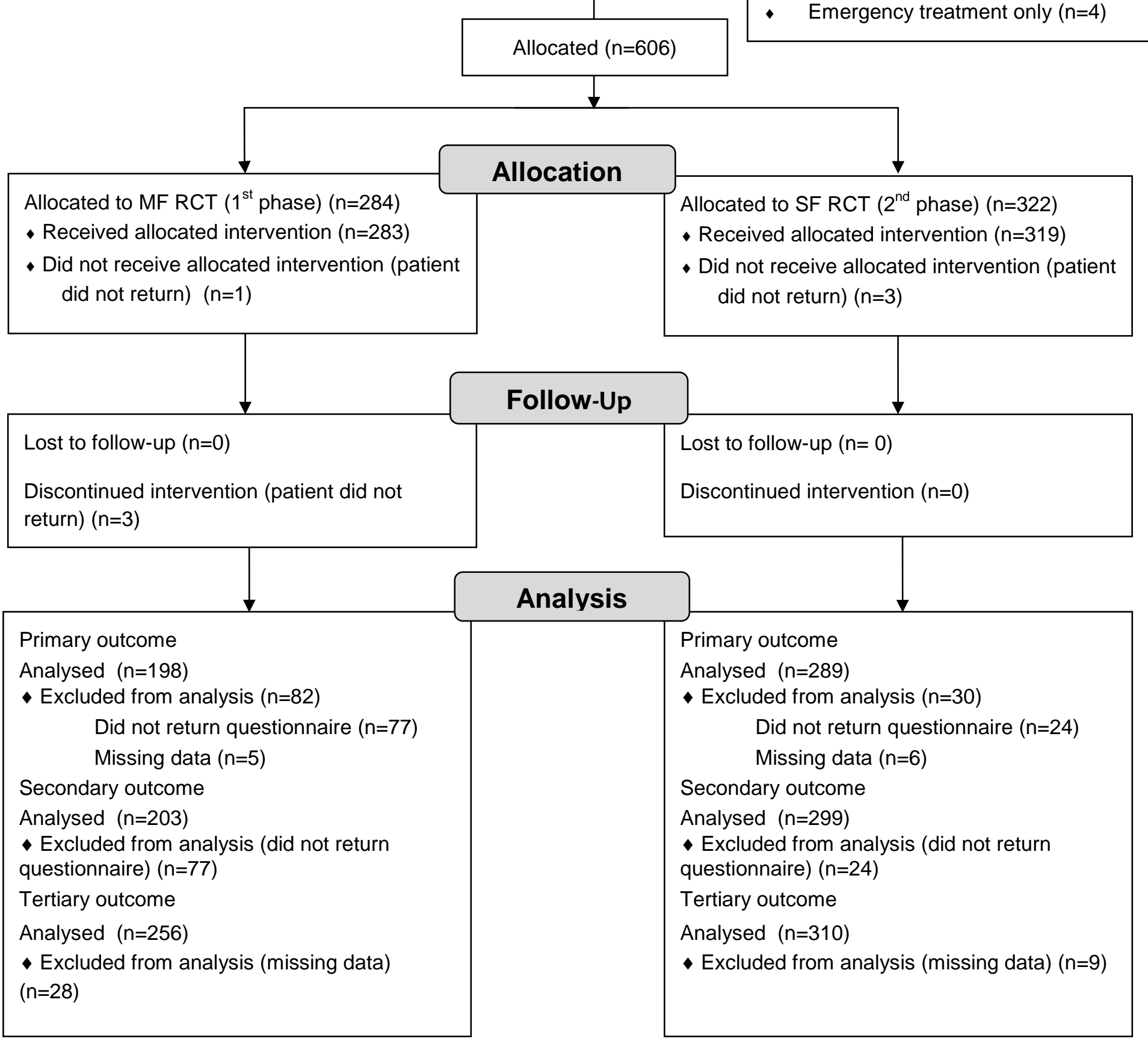

